\title{
Photoplethysmograph Portable Menggunakan Raspberry Pi
}

\author{
Saeful Bahri ${ }^{1}$, Purwono ${ }^{2}$ \\ 1) 2) Teknik Elektro Universitas Muhammadiyah Jakarta \\ Jl. Cempaka Putih Tengah 27 \\ Email: ${ }^{1)}$ saefulb@ftumj.ac.id , 2) 2012420024@ftumj.ac.id
}

\begin{abstract}
ABSTRAK
Metode non-invasive untuk memonitor fungsi jantung yang sederhana adalah Photoplethysmography. Pada tulisan ini diuraikan Photoplethysmography dengan dua sumber cahaya (reflektif dan transmitter), satu fotosensor dengan dua kali pengkondisi sinyal (double BPF). Informasi sinyal detak jantung dimodulasikan pada frekuensi audible yang dihasilkan oleh osilator (IC555 timer) kemudian dikonversi menjadi data digital oleh USB sound card (sebagai ADC). Pemrosesan sinyal dilakukan menggunakan Raspberry Pi dan sofware JavaFX. Bentuk gelombang PPG, pulse, meanRR, sdRR, rMSSD, pNN50 dapat ditampilkan pada layar LCD 5 inch. Gelombang PPG morfologinya sama dengan gelombang $A B P$, dengan akuisi sinyal yang tepat, PPG menawarkan hal baru untuk manajemen penanganan $P A D$ pada penderita diabetes militus, gagal ginjal dan usia lanjut. Dengan alat ini, detak jantung dapat dihitung dengan presentase kesalahan 0.098\%. Pada display dapat ditampilan grafik gelombang yang menyerupai dengan bentuk gelombang masukan dan menjadi masa depan untuk pengganti ABP. Perbandingan pengukuran detak jantung antara alat dengan pulse oximetry menunjukan deviasi antara 0.1 - 0.4 .
\end{abstract}

Kata kunci : Photoplethysmography, non-invasive, ABP, reflektif, transmitter, double BPF, Raspberry Pi, PAD.

\begin{abstract}
A non-invasive method for monitoring simple heart function is Photoplethysmography. In this paper Photoplethysmography is described with two light sources (reflective and transmitter), one photosensor with two signal conditioners (double BPF). The heart rate signal information is modulated at the audible frequency generated by the oscillator (IC555 timer) and then converted to digital data by a USB sound card (as an ADC). Signal processing is done using Raspberry Pi and JavaFX software. $P P G$, pulse, meanRR, sdRR, $r M S S D$, pNN50 waveforms can be displayed on a 5 inch LCD screen. The $P P G$ wave morphology is the same as the ABP wave, with the acquisition of the right signals, $P P G$ offers something new for the management of $P A D$ in patients with diabetes mellitus, kidney failure and old age. With this tool, heart rate can be calculated with a percentage error of $0.098 \%$. On the display can be displayed wave charts that resemble the input waveform and become a future for ABP substitutes. Comparison of heart rate measurements between devices with pulse oximetry shows a deviation between $0.1-0.4$.
\end{abstract}

Keywords: Photoplethysmography, non-invasive, ABP, reflective, transmitter, double BPF, Raspberry Pi, PAD

\section{PENDAHULUAN}

Kesehatan jantung adalah isu yang serius, berdasarkan data WHO (World Health Organization) CVDs atau penyakit kardiovaskuler telah menyebabkan kematian 17.9 juta jiwa setiap tahun, $31 \%$ dari total kematian global, lebih dari $75 \%$ kematian terjadi di negara dengan pendapatan rendah dan menengah, 85\% dari semua kematian akibat CVD disebabkan oleh serangan jantung dan stroke [1]. Untuk mengurangi angka kematian akibat penyakit kardiovaskuler adalah dengan mengetahui kondisi jantung, agar dapat dilakukan treatment apabila ada kelainan. Hal sederhana untuk mengetahui kesehatan jantung yaitu dengan mengukur dan menilai detak jantung (Pulse Rate).
Pulse Rate merupakan salah satu tanda vital pada manusia hidup. Metode paling umum di rumah sakit untuk memantau dan mendokumentasikan kemajuan atau kemunduran kesehatan pasien adalah melaui penilaian terhadap lima tanda vital yaitu : tekanan darah (BP), saturasi oksigen dalam darah (SpO2), pulse rate, pernafasan, dan suhu tubuh [2]. Pengukuran detak jantung (Pulse Rate) dilakukan dengan menghitung detak nadi dalam satu menit, dapat juga diukur menggunakan alat pengukur pulse rate elektronik disebut juga Photoplethysmograph (PPG). PPG adalah metode non-invasive untuk mendeteksi gelombang pulsa kardiovaskuler menggunakan sumber cahaya dan foto detektor [3]. Dijelaskan oleh Denisse Castaneda, PPG adalah 
RESISTOR (Elektronika Kendali Telekomunikasi Tenaga Listrik Komputer) Vol. 3 No. 2 e-ISSN : 2621-9700, p-ISSN : 2654-2684

teknologi non-invasif yang menggunakan sumber cahaya dan fotodetektor di permukaan kulit untuk mengukur variasi volumetrik dari sirkulasi darah [4]. Gelombang pulsa jantung jika diakuisisi dengan tepat dapat memberikan informasi keadaan jantung yang dapat dijadikan dasar assessment kondisi jantung. Informasi yang dapat diambil dari gelombang pulsa jantung diantaranya beat rate, bentuk gelombang pulsa jantung, dan nilai HRV (Heart Rate Variability). Ada dua metode pengukuran HRV yaitu Metode Linear (time domain, frekuensi domain), Metode Non-Linear [5].

Yang paling umum dan mudah untuk pengukuran HRV adalah time domain (meanRR, sdRR, rMSSD, pNN50). Detak jantung (HR) adalah parameter dasar mendiagnosis sinyal EKG berdasarkan variabilitas denyut jantung (HRV) yang dapat juga digunakan sebagai penanda kuantitatif sistem saraf otonom [6]. Informasi detak jantung adalah sesuatu yang penting dan berharga bagi kesehatan, karena salah satu tanda vital adalah detak jantung (pulse rate). Saat ini beberapa produk jam tangan pintar (smart watch) sudah memasang piranti PPG didalamnya dan dapat terhubung dengan applikasi penghitung HRV. Jam tangan pintar ini dijual dengan harga yang relatif mahal. Pada tulisan ini akan membahas rancang bangun PPG portable dan berbiaya relative murah [7]. Berdasarkan penelitan yang dilakukan Tamas Nagy, Rasberry Pi menjadi solusi PPG berbiaya murah. Board Raspberry Pi dengan harga terjangkau, OS tidak berbayar, open source Linux Debian dan javaFX. Dengan demikian alat PPG berbiaya murah dapat terwujud.

\section{METODOLOGI}

Pada penelitian ini menggunakan dua sumber power yaitu Adaptor 5V/3A dan power bank 11000mAh. Pada blok sensor ditempatkan dua sumber cahaya yang dipasang berdampingan dengan photosensor dan berseberangan dengan photosensor (reflektif dan transmitif). Dengan merujuk pada tabel dibawah maka sumber cahaya dipilih menggunakan IR-LED, yang memiliki peak panjang gelombang $\lambda p=940 \mathrm{~nm}$, rendah absorbsi terhadap hemoglobin dan tinggi reflektansinya terhadap kulit atau rendah emisivitasnya terhadap kulit. 
RESISTOR (Elektronika Kendali Telekomunikasi Tenaga Listrik Komputer) Vol. 3 No. 2 e-ISSN : 2621-9700, p-ISSN : 2654-2684

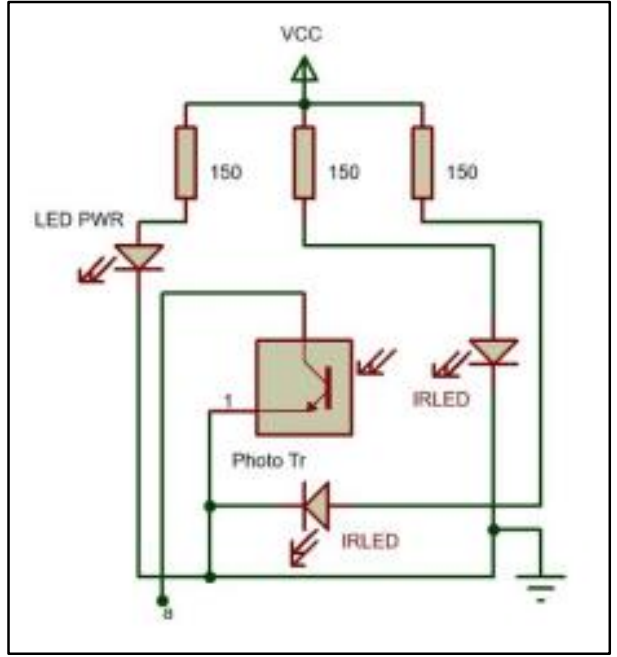

Gambar 3 Skema Dual Mode (Transmitif-Reflektif).

Pada penelitian ini Filter yang digunakan adalah dua kali Band Pass filter yang masing-masing terdiri dari Pasif HPF dan aktif LPF. Untuk dapat menyesuaikan dengan Frekuensi Band PPG dan ketersediaan komponen elektronik dipasaran penelitian ini menggunakan Filter BPF dengan fc $=0.3-6 \mathrm{~Hz}$ dan gain 28 .

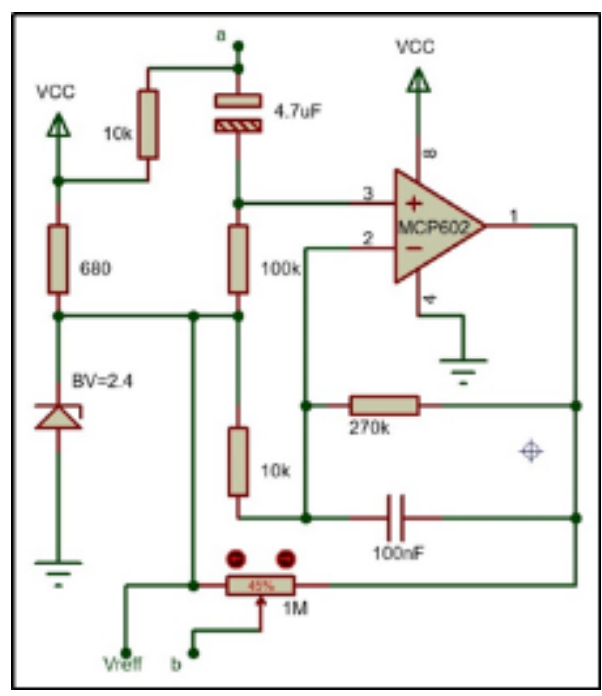

Gambar 4 Schematic Filter Stage 1.

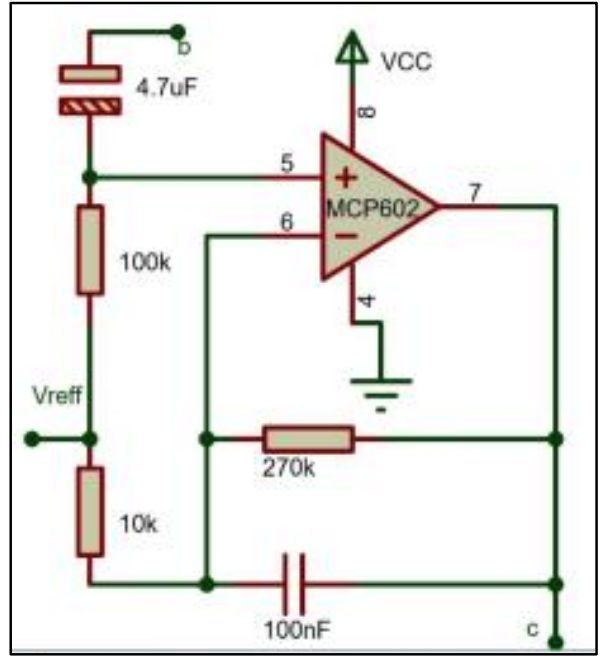

Gambar 5 Schematic Filter Stage2.

\section{Pasif HPF}

$\mathrm{fc}=1 / 2 \pi R C$

$f c=1 /(2 * \pi * 100 \mathrm{~K} \Omega * 0.0000047 \mathrm{~F})=0.33 \mathrm{~Hz} \approx 0.3 \mathrm{~Hz}$

\section{Aktif LPF}

$\mathrm{fc}_{\mathrm{C}}=1 / 2 \pi \mathrm{RC}$

$f c=1 /(2 * \pi * 270 \mathrm{~K} \Omega * 0.0000001 \mathrm{~F})=5.89 \mathrm{~Hz} \approx 6 \mathrm{~Hz}$

Gain $=1+R 1 / R 2=1+270 K / 10 K=28$

Frekuensi respon analog input USB Sound Card adalah $20-20 \mathrm{KHz}$ (audible frekunsi), sedangkan frekuensi PPG berada dibawah 20Hz. Agar sinyal informasi PPG dapat diproses dan diteruskan maka dibutuhkan modulasi. Sinyal PPG dimodulasikan pada sinyal pembawa dengan frekuensi $503.84 \mathrm{~Hz}$, frekuensi ini berada dalam rentang frekuensi audible sehingga dapat diproses oleh sound card. Teknik modulasi yang digunakan adalah frekuensi modulasi. Sinyal modulasi dapat dihasilkan dengan menggunakan IC 555 sebagai osilator. Sinyal infor masi ditumpangkan ke IC 555 melalui Control Voltage (kaki IC nomer 5). 
RESISTOR (Elektronika Kendali Telekomunikasi Tenaga Listrik Komputer) Vol. 3 No. 2 e-ISSN : 2621-9700, p-ISSN : 2654-2684

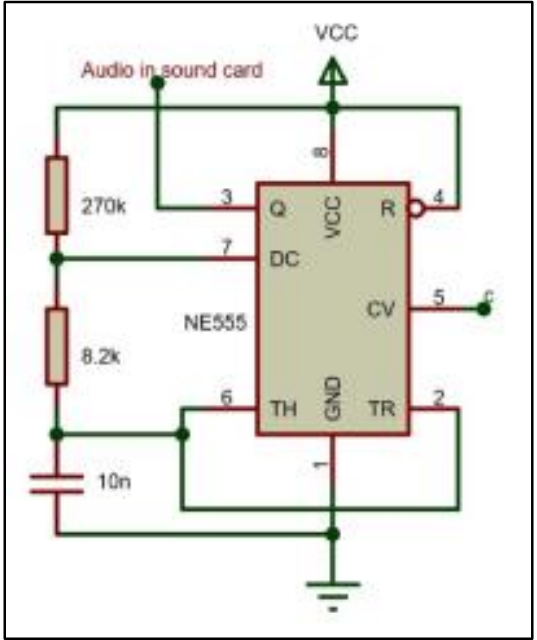

Gambar 6 LMC555 Pulse Position Modulator mode.

Frequency Oscillation

$\mathrm{fc}=1 /(\ln (2) *(\mathrm{RA}+2 * \mathrm{RB}) * \mathrm{C})$

$f_{c}=1 /(0.693 *(270000+2 * 8200) * 0.00000001)$

$f_{c}=503.84 H z$

Board Raspberry Pi tidak menyediakan analog input, dengan demikian diperlukan eksternal ADC untuk mengkonversi data analog menjadi data digital. Perangkat yang paling mudah didapatkan dan kompatibel dengan berbagai macam OS adalah USB sound card. USB sound card memiliki 16-Bit resolusi data.

Untuk memproses sinyal digunakan Raspberry PI sebagai CPU dan sebuah software. Pada penelitian ini digunakan Java script. Sofware Java tidak berbayar sehingga biayanya lebih murah, selain itu memerlukan memori lebih kecil dibandingkan dengan sofware lainya. Origininal software http://www.noise.inf.u-

szeged.hu/Instruments/raspberryplet/,software modifikasi dapat request ke email peneliti.

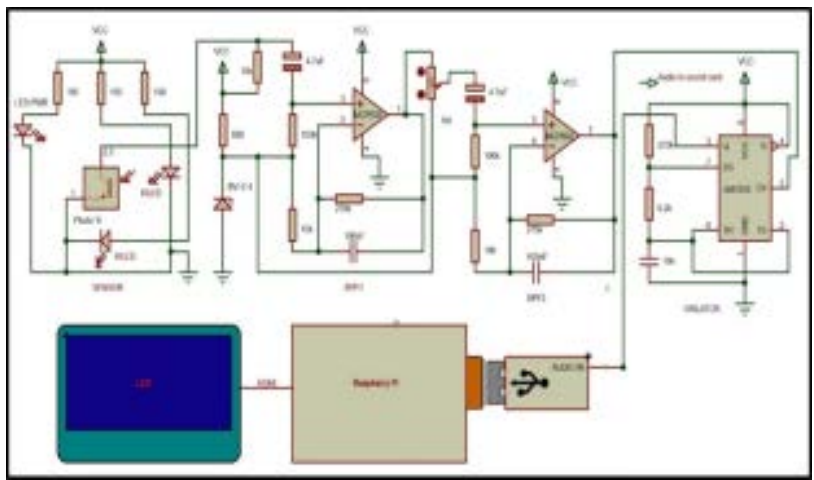

Gambar 7 Skema Lengkap Perancangan.

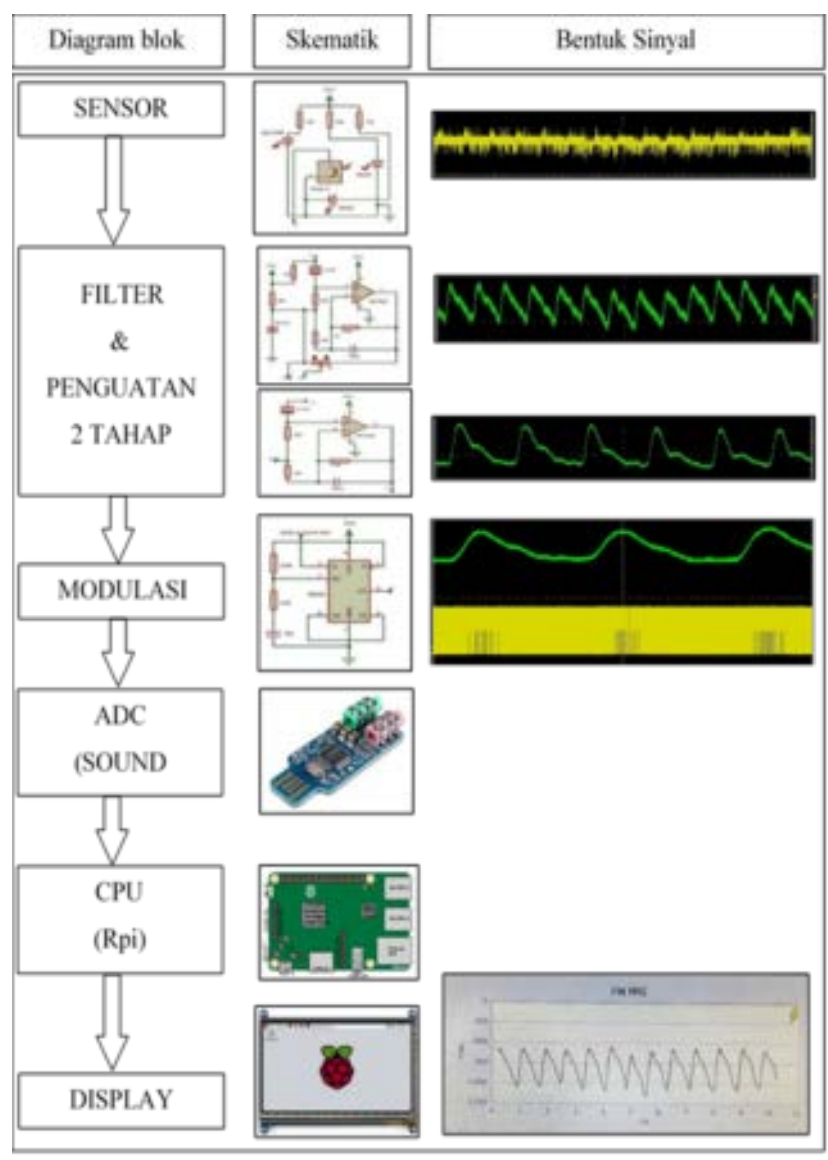

Gambar 8 Proses akuisisi Sinyal PPG

\section{HASIL DAN PEMBAHASAN}

Flowchart pengujian.

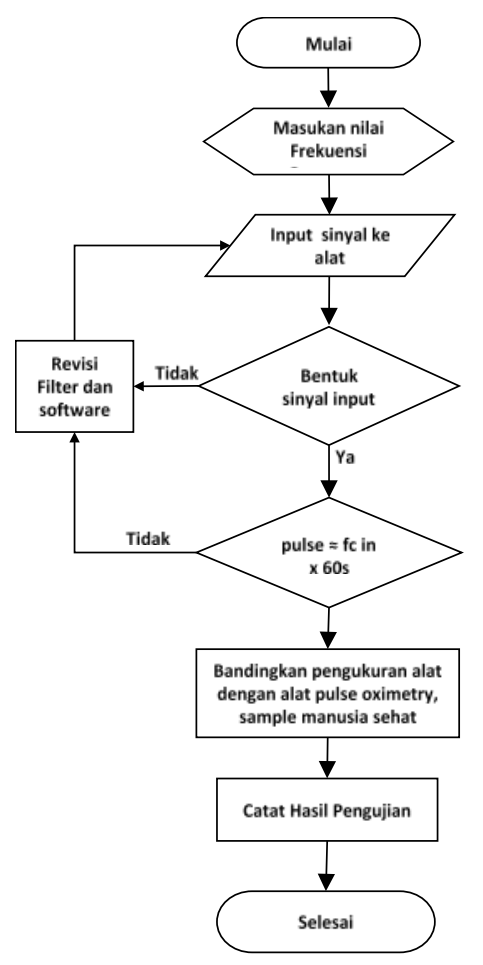


RESISTOR (Elektronika Kendali Telekomunikasi Tenaga Listrik Komputer) Vol. 3 No. 2 e-ISSN : 2621-9700, p-ISSN : 2654-2684

Pengujian awal pada alat menggunakan signal generator untuk memberikan sinyal masukan pada alat dan osciloscoope untuk menampilkan bentuk gelombang pada sinyal masukan. Sedangkan utuk pengujian pengukurran digunakan pulse oximetry sebagai pembanding dan sample uji pada manusia sehat.

Tabel 1 Hasil pengujian tampilan bentuk sinyal.

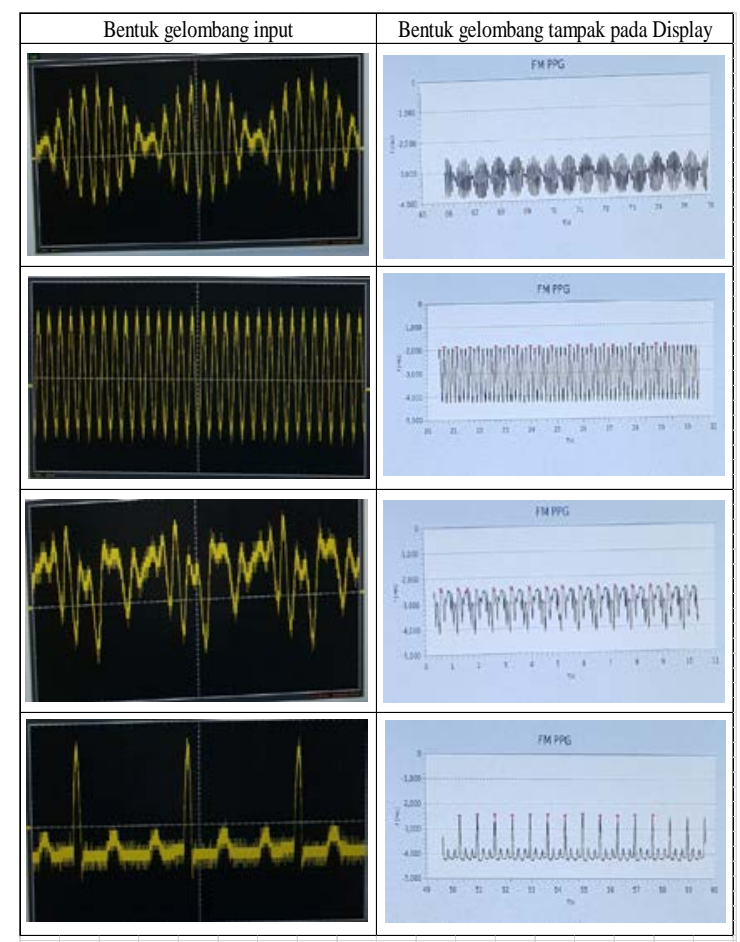

Tabel 2 Pengukuran respon frekuensi

\begin{tabular}{|c|c|c|c|c|}
\hline \multicolumn{2}{|c|}{$\begin{array}{l}\text { Input signal } \\
\text { Generator }\end{array}$} & \multirow{2}{*}{$\begin{array}{l}\text { Pulse } \\
\text { sesuai } \\
\text { rumus } \mathrm{Fc}_{\text {in }} \\
\mathrm{x} 60 \mathrm{~s} \\
\text { (bpm) }\end{array}$} & \multirow{2}{*}{$\begin{array}{l}\text { Display } \\
\text { Alat } \\
\text { Pulse(bpm } \\
\text { ) }\end{array}$} & \multirow{2}{*}{$\begin{array}{l}\text { Devi } \\
\text { asi }\end{array}$} \\
\hline $\begin{array}{l}\text { no. } \\
\text { input }\end{array}$ & $\begin{array}{l}\text { Fc } \\
\text { in }(\mathrm{Hz})\end{array}$ & & & \\
\hline 1 & 0.3 & 18 & 18 & 0 \\
\hline 2 & 0.55 & 33 & 33.9 & 0.9 \\
\hline 3 & 0.8 & 48 & 48 & 0 \\
\hline 4 & 1.05 & 63 & 63 & 0 \\
\hline 5 & 1.3 & 78 & 78 & 0 \\
\hline 6 & 1.55 & 93 & 93 & 0 \\
\hline 7 & 1.8 & 108 & 108 & 0 \\
\hline 8 & 2.05 & 123 & 123 & 0 \\
\hline 9 & 2.3 & 138 & 138 & 0 \\
\hline 10 & 2.55 & 153 & 153.1 & 0.1 \\
\hline
\end{tabular}

\begin{tabular}{|c|c|c|c|c|}
\hline 11 & 2.75 & 165 & 165 & 0 \\
\hline $\mathrm{AV}$ & & 92.727 & 92.818 & \\
\hline
\end{tabular}

Rata-rata pulse alat $\quad$ : 92.818------------------- $\rightarrow$ A

Rata-rata pulse rumus : 92.727 --_-_----------- $\rightarrow$ R

Kesalahan\% : : ------------------------- $\rightarrow$ K

$\mathrm{K}=(\mathrm{A}-\mathrm{R}) / \mathrm{R} * 100 \%$

$K=(92.818-92.727) / 92.727 * 100 \%=0.098 \%$

Tabel 3 Hasil pengukuran sample manusia sehat

\begin{tabular}{|c|c|c|c|c|c|c|c|c|c|}
\hline \multirow[b]{2}{*}{$\frac{\frac{0}{O}}{\frac{0}{E}}$} & \multirow[b]{2}{*}{ 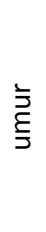 } & \multirow[b]{2}{*}{$\frac{\frac{1}{d}}{\frac{1}{c}}$} & \multirow{2}{*}{ 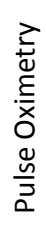 } & \multicolumn{5}{|c|}{ Alat } & \multirow{2}{*}{ 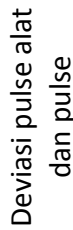 } \\
\hline & & & & 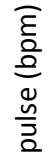 & 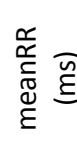 & $\begin{array}{l}\stackrel{\Upsilon}{\simeq} \\
\stackrel{c}{0}\end{array}$ & $\begin{array}{l}\text { D્n } \\
\text { E્ }\end{array}$ & $\begin{array}{l}\frac{\widehat{a}}{0} \\
\text { 은 } \\
2 \\
2\end{array}$ & \\
\hline 1 & 35 & P & 71 & 71.1 & 844.3 & 41.4 & 63 & 58.3 & 0.1 \\
\hline 2 & 37 & $\mathrm{~L}$ & 86 & 86 & 697.6 & 94.7 & 163.3 & 71.4 & 0 \\
\hline 3 & 34 & $\mathrm{P}$ & 74 & 74 & 810.3 & 155 & 171.5 & 15.8 & 0 \\
\hline 4 & 26 & $\mathrm{~L}$ & 67 & 67.4 & 890.2 & 20.4 & 26.1 & 5.9 & 0.4 \\
\hline 5 & 38 & L & 84 & 84.4 & 710.5 & 16.2 & 25.7 & 6.9 & 0.4 \\
\hline 6 & 29 & L & 78 & 78.4 & 765.5 & 23.6 & 34.3 & 21.4 & 0.4 \\
\hline 7 & 26 & L & 92 & 92.2 & 650.7 & 24.9 & 30.6 & 12.5 & 0.2 \\
\hline 8 & 26 & $\mathrm{~L}$ & 88 & 87.9 & 682.8 & 27.3 & 33.4 & 13.6 & 0.1 \\
\hline 9 & 23 & $\mathrm{~L}$ & 74 & 74.4 & 806.2 & 24.2 & 39 & 15.8 & 0.4 \\
\hline 10 & 25 & L & 85 & 85 & 705.9 & 37.9 & 54.9 & 50 & 0 \\
\hline 11 & 26 & $\mathrm{~L}$ & 98 & 98 & 612.4 & 24.3 & 27.7 & 9.1 & 0 \\
\hline 12 & 27 & L & 48 & 48 & 1250 & 38.7 & 67.3 & 66.7 & 0 \\
\hline
\end{tabular}

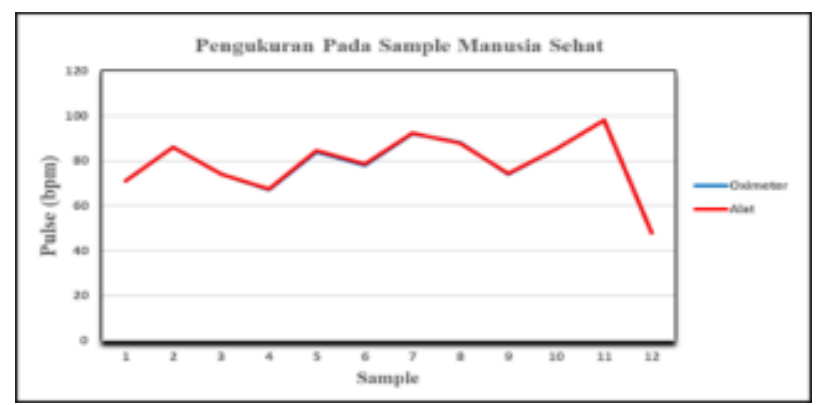

Gambar 9 Grafik pengukuran, sample manusia sehat.

4 KESIMPULAN 
RESISTOR (Elektronika Kendali Telekomunikasi Tenaga Listrik Komputer) Vol. 3 No. 2 e-ISSN : 2621-9700, p-ISSN : 2654-2684

Berdasarkan

Pengujian

alat

Photoplethysmograph ini didapat kesimpulan sebagai berikut :

1. Detak jantung dengan Frekuensi $0.3-2.75 \mathrm{~Hz}(18$ - 165 bpm) dapat dihitung dengan baik dan hasil mendekati perhitungan rumus, dengan kesalahan $0.098 \%$.

2. Pada display dapat ditampilan grafik gelombang yang menyerupai dengan bentuk gelombang masukan.

3. Perbandingan pengukuran dengan alat yang umum digunakan tenaga medis, menunjukan hasil yang mendekati, dengan deviasi antara 0.1 -04 .

\section{DAFTAR PUSTAKA}

[1] "https: //www.who.int /cardiovascular diseases/en/,” World Heart Day, 2018. - Google Search.”

https://www.google.com/search?client=firefox -b-

d\&q=https\%3A+\%2F\%2Fwww.who.int $+\% 2 F$ cardiovascular+diseases\%2Fen\%2F\%2C\%E2 \%80\%9D+World+Heart+Day\%2C+2018. (accessed Sep. 12, 2020).

[2] M. Cardona-Morrell et al., "Vital signs monitoring and nurse-patient interaction: A qualitative observational study of hospital practice," International journal of nursing studies, vol. 56, pp. 9-16, 2016.

[3] "New Circuit Design to Measure Photoplethysmography | IJRRPAS." http://www.ijrrpas.com/article/new-circuitdesign-measure-photoplethysmography (accessed Jul. 28, 2020).

[4] D. Castaneda, A. Esparza, M. Ghamari, C. Soltanpur, and H. Nazeran, "A review on wearable photoplethysmography sensors and their potential future applications in health care," International journal of biosensors \& bioelectronics, vol. 4, no. 4, p. 195, 2018.

[5] "(PDF) Heart rate variability: Highlights from hidden signals,” ResearchGate. https://www.researchgate.net/publication/3292 23648_Heart_rate_variability_Highlights_fro m_hidden_signals (accessed Sep. 12, 2020).

[6] “(PDF) HEART RATE VARIABILITY ANALYSIS DUE TO ACUPUNCTURE STIMULATION,” ResearchGate. https://www.researchgate.net/publication/3168 79815_HEART_RATE_VARIABILITY_AN

\author{
ALYSIS_DUE_TO_ACUPUNCTURE_STIM \\ ULATION (accessed Sep. 12, 2020).
}

[7] T. Nagy and Z. Gingl, "Low-cost photoplethysmograph solutions using the Raspberry Pi," in 2013 IEEE 14th International Symposium on Computational Intelligence and Informatics (CINTI), 2013, pp. 163-167.

[8] E. Angelopoulou, "Understanding the color of human skin," in Human vision and electronic imaging VI, 2001, vol. 4299, pp. 243-251.

[9] C. Ash, M. Dubec, K. Donne, and T. Bashford, "Effect of wavelength and beam width on penetration in light-tissue interaction using computational methods," Lasers in medical science, vol. 32, no. 8, pp. 1909-1918, 2017. 